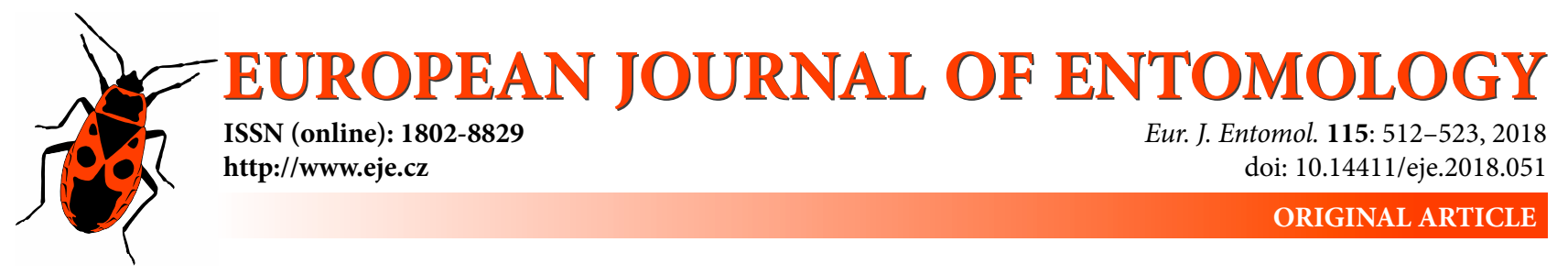

\title{
Survey and DNA barcoding of flat bugs (Hemiptera: Aradidae) in the Tanzanian Forest Archipelago reveal a phylogeographically structured fauna largely unknown at the species level
}

\author{
VASILY V. GREBENNIKOV ${ }^{1}$ and ERNST HEISS ${ }^{2}$ \\ ${ }^{1}$ Canadian Food Inspection Agency, K.W. Neatby Building, 960 Carling Ave., Ottawa, ON, K1A 0C6, Canada; \\ e-mail: vasily.grebennikov@canada.ca \\ ${ }_{2}$ Tiroler Landesmuseum, Josef-Schraffl-Strasse 2a, A-6020 Innsbruck, Austria; e-mail: aradus@aon.at
}

Key words. Heteroptera, Aradidae, Mezirinae, microptery, Tanzania, barcoding, phylogeography, Eastern Arc Mountains

\begin{abstract}
We report results of a faunal survey of Aradidae flat bugs sampled by sifting litter in 14 wet and discrete Tanzanian primary forests (= Tanzanian Forest Archipelago, TFA) of different geological origins and ages. Images, locality data and, when available, DNA barcoding sequences of 300 Aradidae adults and nymphs forming the core of the herein analyzed data are publicly available online at dx.doi.org/10.5883/DS-ARADTZ. Three Aradidae subfamilies and seven genera were recorded: Aneurinae (Paraneurus), Carventinae (Dundocoris) and Mezirinae (Afropictinus, Embuana, Linnavuoriessa, Neochelonoderus, Usumbaraia); the two latter subfamilies were also represented by specimens not assignable to nominal genera. Barring the six nominal species of Neochelonoderus and Afropictinus described earlier by us from these samples and representing 11 of the herein defined Operational Taxonomic Units (OTU), only one of the remaining 52 OTUs could be assigned to a named species; the remaining 51 OTUs (81\%) represent unnamed species. Average diversity of Aradidae is 4.64 species per locality; diversity on the three geologically young volcanoes (Mts Hanang, Meru, Kilimanjaro) is significantly lower (1.33) than on the nine Eastern Arc Mountains (5.67) and in two lowland forests (5). Observed phylogeographic structure of Aradidae in TFA can be attributed to vicariance, while the depauperate fauna of Aradidae on geologically young Tanzanian volcanoes was likely formed anew by colonisation from nearby and geologically older forests.
\end{abstract}

\section{INTRODUCTION}

DNA data generation and analysis targeting the cytochrome oxidase barcoding fragment $(658 \mathrm{bp}$ of COI-5' mitochondrial gene, Hebert et al., 2003a; b) has become established as a popular and efficient tool with various applications. Many such studies report DNA barcodes targeting members of a certain clade from a certain territory; some of the notable examples are Central European beetles (Hendrich et al., 2015) and bees (Schmidt et al., 2015), North American Noctuoidea moths (Zahiri et al., 2017), Australian hawkmoths (Rougerie et al., 2014), Neotropical Gracillariidae moths (Lees et al., 2013) and European bugs (Raupach et al., 2014; Havemann et al., 2018). Here we follow this conventional approach by reporting a DNA barcode library of Aradidae flat bugs thoroughly sampled throughout the Tanzanian Forest Archipelago (TFA) and use this newly generated dataset to test a set of hypotheses (Collins \& Cruickshank, 2013).

The family Aradidae (Figs 1B-D, 2-5) is a well-supported cosmopolitan clade of about 280 recent genera and some 2,000 recent species (numbers approximated from Grebennikov \& Heiss, 2014). The family is still inconsis- tently treated either with (Cassis \& Schuh, 2010) or without (Marchal \& Guilbert, 2015) the odd family Termitaphididae, a clade of 13 exclusively termitophilous, blind and wingless small-bodied pantropical species, either recent or extinct. Wet tropical forests tend to harbour the greatest diversity of Aradidae. The most recent common ancestor of Aradidae and its sister group (likely formed by the rest of the superfamily Pentatomomorpha, Schuh \& Slater, 1995; Grazia et al., 2008; Yao et al., 2012; Liu et al., 2018) lived in the late Triassic (about $214 \mathrm{Ma}$, Song et al., 2016), while the Aradidae crown group dates from the late Jurassic (about 162 Ma, Song et al., 2016). The eight Aradidae subfamilies are Aneurinae, Aradinae, Calisiinae, Carventinae, Chinamyersiinae, Isoderminae, Mezirinae and Prosympiestinae. Mezirinae include more than half of the species in this family, Prosympiestinae is of doubtful monophyly (Marchal \& Guilbert, 2015), while Calisiinae likely forms the sister to the remaining subfamilies (Song et al., 2016). Detailed relationships within the family have remained mostly unresolved. The easy-to-recognize appearance of Aradidae, the existence of a classical and well-illustrated global taxonomic treatment (Usinger \& Matsuda, 1959) 
and a catalogue (Kormilev \& Froeschner, 1987) stimulated studies on the regional diversity of Aradidae, such as those by Monteith (1997) in Australia, Larivière \& Larochelle (2006) in New Zealand and Baňař \& Heiss (2018) in Madagascar. The degree to which aradid biodiversity has been described varies greatly among regions, and much descriptive work remains to be done in Tanzania and East Africa in general (Heiss, 2013). From an international trade perspective, Aradidae are frequently intercepted on sea-transported commodities (Chérot et al., 2011) such as wood/ bark products, fruits and cut flowers, however their species level identification is difficult because of inadequate taxonomy. Smith-Pardo \& Beucke (2015) documented that due to the lack of morphological and DNA diagnostic tools, only 65 among the total of 128 Aradidae interceptions made between 1992 and 2013 at the United States ports of entry were identified beyond the family level. All in all, flat bugs are just another widely distributed medium-sized monophyletic insect family suffering from taxonomic and phylogenetic neglect.

The Tanzanian Forest Archipelago (TFA), the geographical focus of this paper, is a remarkable biological phenomenon. It is formed by a dispersed cluster of wet and cool closed-canopy rainforests of variable size and altitude, separated by much greater areas of highly contrasting dry and hot savannah. Based on their age and genesis TFA forests fall into two distinct groups. One consists of ancient forests of either the Eastern Arc Mountains (EAM, Lovett \& Wasser, 1993; Newmark, 2002) or those of the lowland coastal plain, both tracing their uninterrupted existence since at least the Miocene pan-African forest (>30 Myr, Hamilton $\&$ Taylor, 1991; deMenocal, 2004). The second group is formed by forests that came into existence within the last 2 Myr on geologically young volcanoes, such as Mts Kilimanjaro and Meru associated with the East African Rift (Nonnotte et al., 2008). These contrasting spatial settings facilitate the testing of the classic phylogeographic riddle as to what degree dispersal versus vicariance was the main driving force behind the distribution of organisms critically dependant on such a discrete and widely dispersed habitat (438 hits in a Google Scholar search using "Eastern Arc Mountains" and "phylogeography” on July 12, 2018).

This study of Aradidae in TFA hinges on the advantageous capacity of DNA barcoding to rapidly generate sufficient data to test hypotheses and present the results as a phylogenetic tree. Reliability of such trees at deeper levels is compromised by the well-documented shortcomings of a single quickly saturating and maternally inherited DNA marker such as COI (Funk \& Omland, 2003). A significant and herein utilized practical advantage of the DNA barcoding approach is its independence from the pre-existing taxonomic framework, which makes this tool particularly applicable for studying poorly known and taxonomically neglected faunas, such as Aradidae from TFA. Instant online availability of all DNA barcoding data, including sequences, specimen images and geographical data, renders this tool particularly attractive and useful.
The goal of this study is, therefore, to perform a faunal survey of TFA Aradidae by generating their DNA barcode data. The first step in this work is to document the currently almost unknown diversity of Aradidae in TFA using DNA barcoding and then to use the data to test five hypotheses (H1 to H5):

H1: Aradidae in Tanzania are well known taxonomically at the generic and species levels.

H2: Shallow clades of Aradidae in TFA are geographically structured.

H3: All the phylogeographic structure of Aradidae in TFA can be attributed to vicariance.

H4: Aradidae fauna on geologically young Tanzanian volcanoes was formed anew and after volcanic highlands and their forests came into existence about two million years ago.

H5: If H4 is supported, then this process was driven by colonization from nearby and geologically older TFA forests.

\section{MATERIAL AND METHODS}

\section{Specimen sampling, storing and coding}

Adults and nymphs of Tanzanian Aradidae were obtained from samples of litter (Fig. 1F) collected at 14 TFA localities (Fig. 1A). Forest litter (Fig. 1E) was sifted through a hand-held sifter (Fig. 1G) and live specimens were subsequently extracted by suspending the fine litter fraction $(<7 \times 7 \mathrm{~mm})$ in Winkler funnels. All 300 specimens were imaged (Fig. S1 in supplementary files) and uniquely linked to one of 130 samples (Fig. 1F) using two-letter and two-digit codes (explained in Table 1 in Grebennikov, 2017). Non-Tanzanian specimens included for comparative purposes (see below) were assembled from different sources. Identification to the lowest possible taxonomic rank (mainly to genus, occasionally to species or to subfamily) were done by EH based on closest match with authoritatively identified voucher specimens stored in his collection (CEHI, Ernst Heiss' Collection, Tiroler Landesmuseum, Innsbruck, Austria). Specimens are stored in either CEHI (98 non-Tanzanian specimens coded in the format BIOUG0209X-XXX and abbreviated in Figs 2-4 to EHX-XXX; previously reported in Grebennikov \& Heiss, 2014) or in the Canadian National Collection of Insects, Arachnids and Nematodes, Ottawa, Canada (CNC, codes are in the format CNCCOLVG0000XXXX abbreviated to the last four digits as in Figs 2-4; either reported in Heiss \& Grebennikov, 2015, 2016, or new).

\section{Hypotheses testing}

To bring a DNA barcode library report into the realm of science (Popper, 1959), and as recommended by Collins \& Cruickshank (2013), the herein released data, including the faunal survey counts and DNA barcode sequences, are used to test five hypotheses mentioned in the Introduction. The methodology is as follows:

H1: calculate the proportion of species of Aradidae successfully assigned to an existing Linnaean nominal genus and/or species of the total OTUs detected in the Tanzanian samples;

H2: assess whether terminal clades recovered in the Maximum Likelihood (ML) analysis are formed by specimens from the same forest of the 14 sampled;

H3: document reciprocal monophyly of geographically defined clades; the latter is considered the standard signature of vicari- 


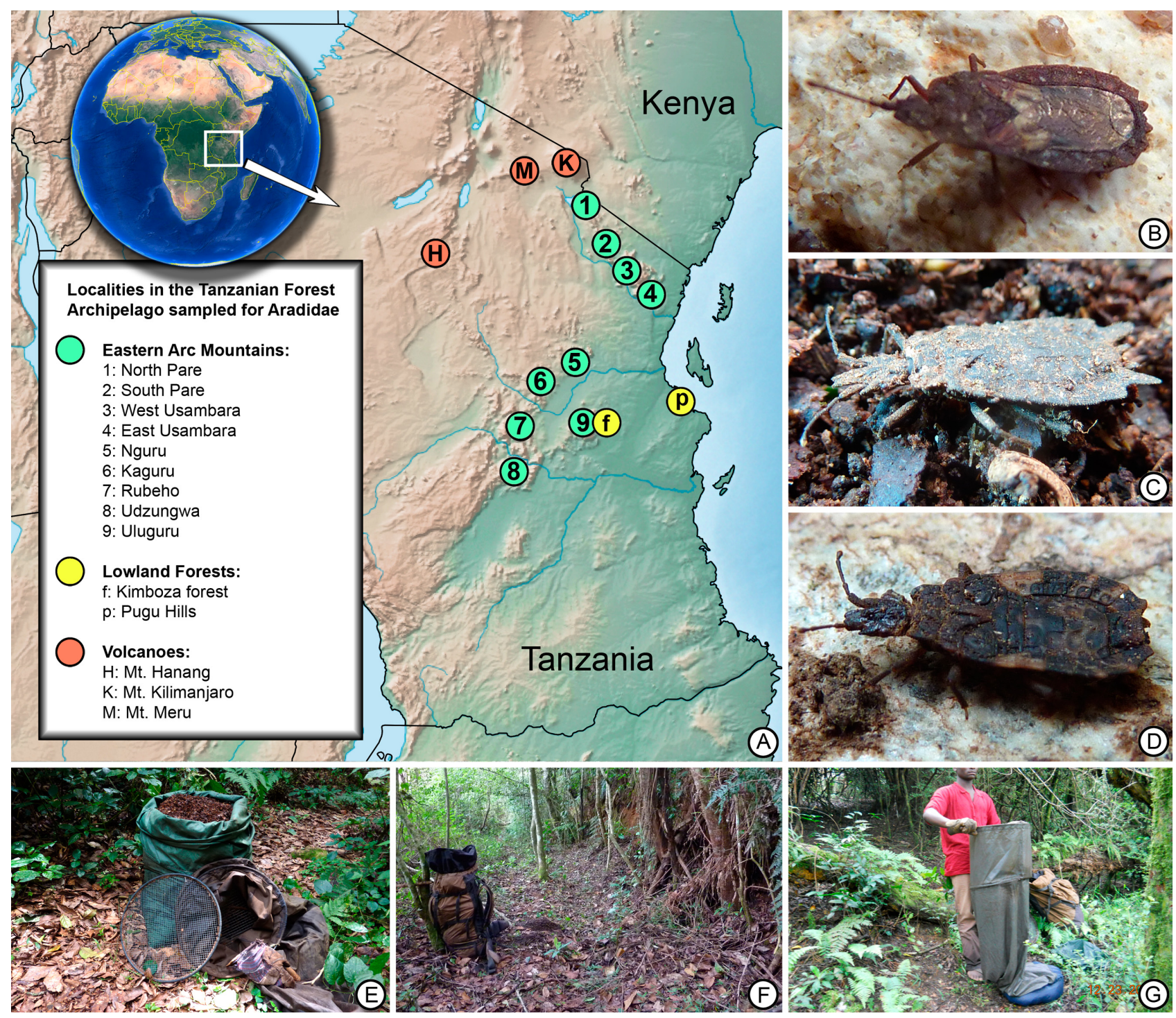

Fig. 1. A - map showing the localities in the Tanzanian Forest Archipelago sampled; B - Mezirinae specimen 5710 (not DNA barcoded) from Pugu Hills; C - Usumbaraia sp. from West Usambara, U; D - Afropictinus idas Heiss \& Grebennikov, 2016 from East Usambara; E sample WU01 in West Usambara; F - locality of sample WU07 in West Usambara; G - locality of sample RB05 in Rubeho.

ance of a widespread ancestor (Heads, 2014: 6), while deviations from this pattern might suggest long-range dispersal;

H4: compare the diversity of Aradidae on young volcanoes to that of all other sampled TFA localities (= old forests);

H5: detect whether Aradidae from young volcanoes are more closely related to those from the nearby EAM forests, than to those from other forests.

\section{DNA sequencing, data availability and three public datasets}

From a total of about five hundred specimens of freshly sampled TFA Aradidae, 300 were selected under a dissecting microscope for DNA barcoding. Sequencing of the DNA barcode fragment of these specimens (and of 234 non-Tanzanian specimens) was performed in a commercial laboratory "Canadian Center for DNA Barcode" (CCDB, http://www.ccdb.ca/) at the University of Guelph, Ontario, Canada, following the standard laboratory protocol (Ivanova et al., 2014, 2006). Two primer pairs were used to amplify the DNA barcoding fragment (Table 2 in Grebennikov, 2017). From a total of 534 specimens of Aradidae subjected to DNA barcoding, 387 resulted in DNA sequences $>200$ bp (of them, 209 were those from Tanzania and they formed a dataset for a Neighbour Joining analysis, see below) and 295 resulted in sequences $>500 \mathrm{bp}$. These 295 sequences were selected for the Maximum Likelihood (ML) analysis (described below); of them, 167 sequences represented Tanzanian specimens and 128 were of non-Tanzanian origin. Among the $295>500$ bp sequences, 96 non-Tanzanian sequences were reported by Grebennikov \& Heiss (2014), one Tanzanian Neochelonoderus Hoberlandt, 1967 sequence was reported by Heiss \& Grebennikov (2015), while 22 Tanzanian and one Ethiopian sequence of Afropictinus Heiss, 1986 were reported by Heiss \& Grebennikov (2016); the remaining 175 sequences are newly generated (140 from Tanzania, 14 from Vietnam, nine from Ethiopia, four from Cameroon and three from China). Representatives of Mezirinae dominated the ML matrix (223 among a total of 295, 149 among a total of 167 from Tanzania). All herein utilized data consisting of images of specimens, information on their localities and, when available, DNA barcode sequences and trace files, are digitally deposited in the Barcode of Life Data System (BOLD, Ratnasingham \& Hebert, 2007) and publicly available through three partly overlapping datasets, each designed to serve a unique purpose:

dataset ARADTZ available online at dx.doi.org/10.5883/DSARADTZ contains data from all 300 freshly sampled specimens 


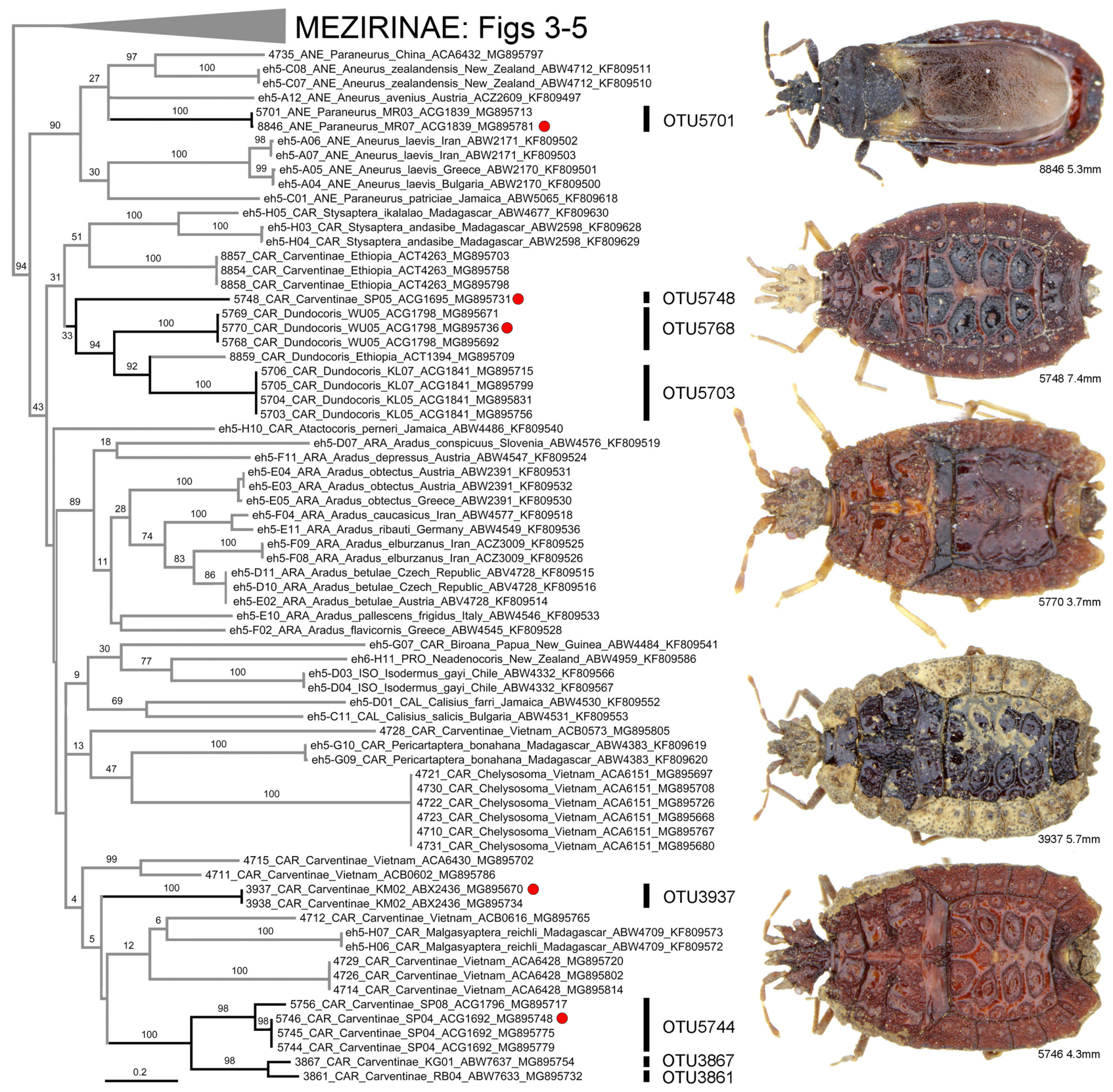

Fig. 2. Maximum Likelihood inference phylogram of non-Mezirinae flat bugs (Aradidae) using the DNA barcoding fragment. Tanzanian specimens are in black. Terminals are arranged in Operational Taxonomic Units (OTUs). Terminal labels consist of a specimen number followed by taxonomic information (a three letter subfamily abbreviation with, when available, genus and species), followed by geographic information (country of origin or, for Tanzanian specimens only, a two-letter two-digit sample code), BIN number and GenBank accession number. Red dots denote illustrated terminals.

of Aradidae from Tanzania submitted for DNA barcoding (of them, 91 specimens are without DNA barcode data) and are used to test hypothesis $\mathrm{H1}$;

dataset ARADBARC available online at dx.doi.org/10.5883/ DS-ARADBARC contains data from all 209 freshly sampled specimens of Aradidae from Tanzania with DNA barcode sequences $>200 \mathrm{bp}$, which were used in the BOLD Neighbour Joining (NJ) analysis (see below) to partly test hypotheses $\mathrm{H} 2-\mathrm{H} 5$;

dataset ARADIDAE available online at dx.doi.org/10.5883/ DS-ARADIDAE contains data from all 295 specimens of Aradidae from Tanzania (167) and from the rest of the World (128) with DNA barcode sequences $>500 \mathrm{bp}$, which were used in the Maximum Likelihood (ML) analysis (see below) to partly test hypotheses $\mathrm{H} 2-\mathrm{H} 5$.

\section{Neighbour Joining analysis of the 209 terminals $>\mathbf{2 0 0}$ bp Tanzanian dataset}

Phenetic clustering was done using the BOLD online engine using the NJ method, without rooting and utilizing the Kimura 2-parameter. Its main purpose was to generate and make available a Tanzania-only DNA barcode dataset (see above) and to assign 42 Tanzanian specimens with short sequences $(200-500 \mathrm{bp})$ to those having longer sequences and thus elucidate their specieslevel identity for a subsequent faunal count.

\section{Maximum Likelihood analysis of the 295 terminals $>500$ bp World dataset}

Sequence alignment was trivial and introduced no insertions or deletions. Phylogenetic analysis was done using the CIPRES 


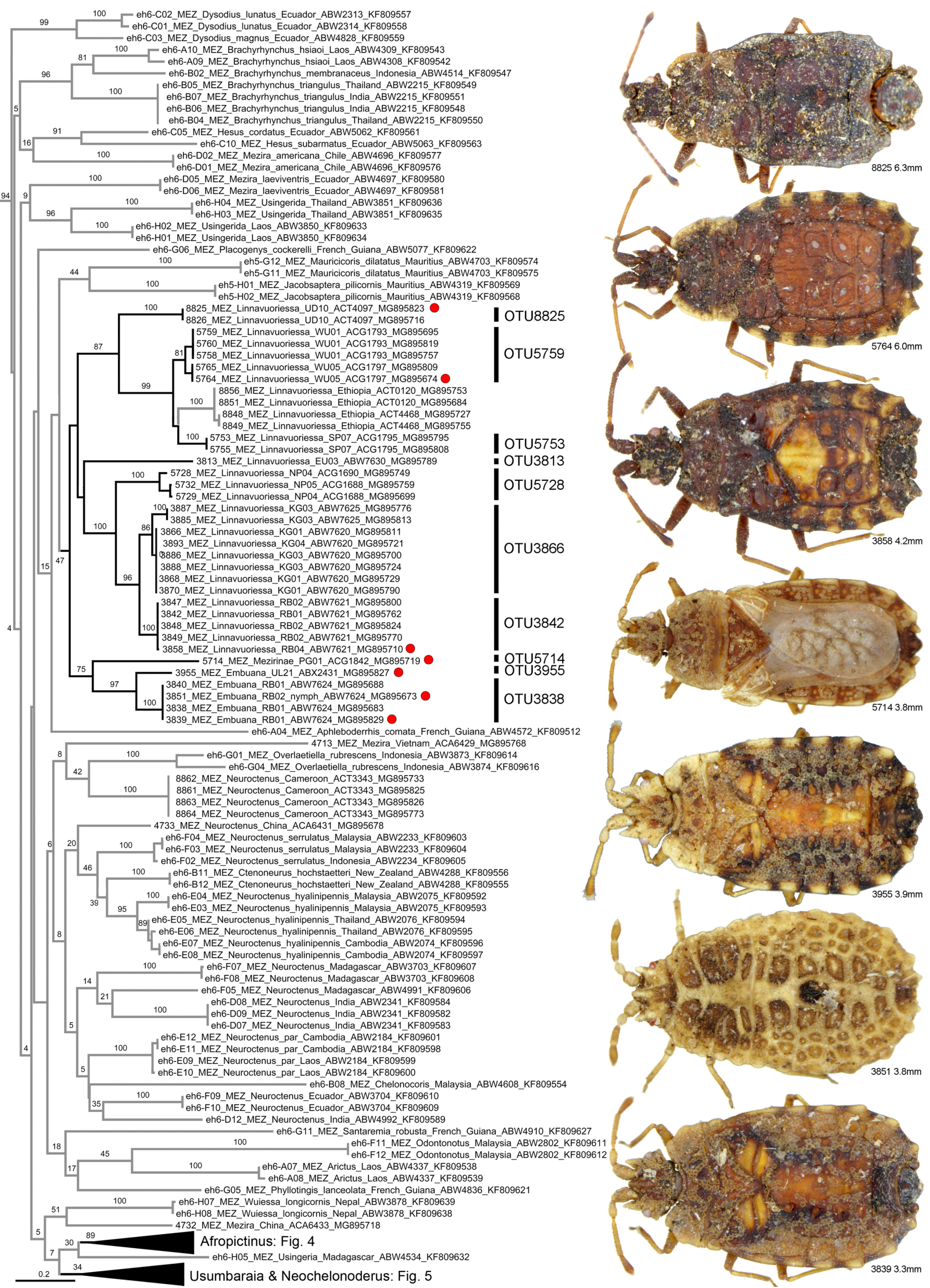

Fig. 3. Maximum Likelihood inference phylogram of Mezirinae flat bugs (Aradidae) using the DNA barcoding fragment (continued from Fig. 2). 

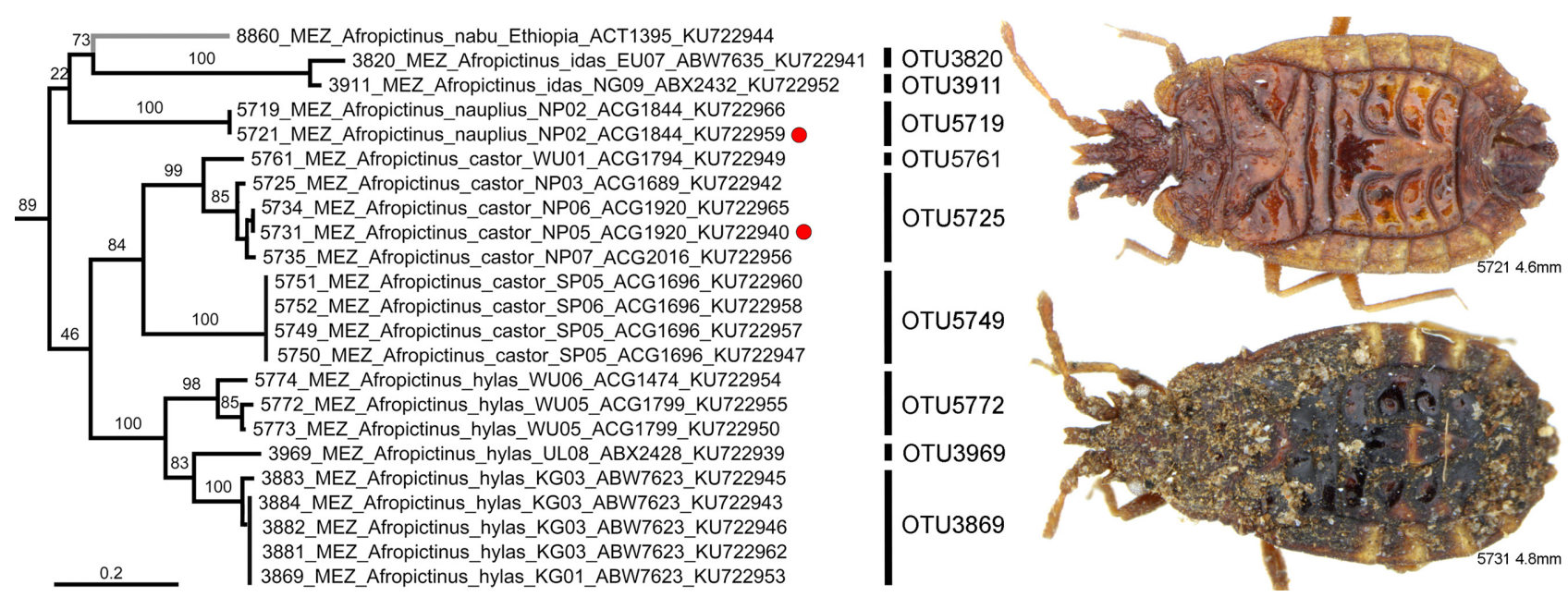

Fig. 4. Maximum Likelihood inference phylogram of Afropictinus flat bugs (Aradidae: Mezirinae) using the DNA barcoding fragment (continued from Figs 2-3).

Science Gateway (Miller et al., 2010) and the ML method. Topologies were generated using RAxML 7.2.7 (Stamatakis et al., 2008), with the default parameters and the GTR $+\mathrm{G}$ nucleotide substitution model. Clade support values were obtained with 1000 parametric bootstrap replicates (Felsenstein, 1985). Since monophyly of Aradidae is not herein doubted and the subfamily interrelationships are not tested, the resulting consensus topology was visualized and rooted arbitrarily between the largest and monophyletic Mezirinae and the rest of the tree using FigTree1.4 (Rambaut, 2014).

Operational Taxonomic Units (OTU) as candidate species, a provisional tool to document and compare the diversity of TFA Aradidae

A Linnaean species, a universally accepted unit for counting biological diversity, cannot be consistently used for TFA Aradidae due to the lack of a pre-existing taxonomic framework. Except for two genera taxonomically revised by us using some of the herein reported specimens (Neochelonoderus by Heiss \& Grebennikov, 2015 and Afropictinus by Heiss \& Grebennikov, 2016), only one of the TFA Aradidae could be assigned to a named species. A temporary alternative to a Linnaean species has, therefore, to be herein introduced and employed. Ideally it should meet all three primary taxon-naming criteria (Vences et al., 2013): monophyly of the taxon in an inferred species tree, clade stability and be phenotypically diagnosable. Our main practical challenge was the acute data incompatibility. Indeed, among 300 TFA specimens analyzed, only 209 have DNA barcode sequences $>200 \mathrm{bp}$ and only 167 of them have DNA barcode sequence $>500 \mathrm{bp}$. To consistently assign all 300 TFA specimens to a unit comparable to a Linnaean species, we defined Operational Taxonomic Units (OTUs), which are considered to be unnamed candidate species. Like a Linnaean species, they are formed by one or more specimens meeting, depending on data availability, any of the three following combinations of criteria:

167 TFA specimens with DNA barcode sequences $>500$ bp and thus meeting the minimal length criterion for the BOLD algorithm to group them into clusters with Barcode Index Numbers (BIN, Ratnasingham \& Hebert, 2013) were grouped in OTUs consisting of all sympatric specimens forming the most inclusive terminal clade recovered in the ML analysis (normally represented by a single BIN, but in a few cases two or three sympatric BINs of morphologically similar specimens formed the same monophyletic OTU); in infrequent cases when allopatric speci- mens (= those from more than one TFA locality) share the same $\mathrm{BIN}$, they are assigned to the same OTU;

42 TFA specimens with short DNA barcodes (200-500 bp), which do not meet the minimal length BIN criterion, were assigned to existing OTUs formed by sympatric specimens with a BIN (see above) using NJ clustering;

91 TFA specimens with no DNA data (= for whom our attempts to generate DNA barcode data failed) were assigned to existing OTUs, which were formed by sympatric and morphologically most similar specimens. In situations when no such OTU preexisted, new OTUs were formed.

Generated OTUs were named using the three letters 'OTU' and four digit codes, the latter the same as one of the included specimens (Figs 2-5, Fig. S1).

\section{Analysis limitations}

Except for two taxonomically revised small genera (Neochelonoderus and Afropictinus, see Heiss \& Grebennikov, 2015, 2016, respectively), no attempt was made to utilize our data for specimen identification and for species discovery (Collins \& Cruickshank, 2013). The former task is currently hardly possible due to the lack of an adequately large DNA library derived from reliably identified (= name-bearing) specimens, while the latter was outside the scope of the present study due to time and resource limitations.

\section{RESULTS}

\section{Phylogenetic analysis of Aradidae}

The ML tree (Figs 2-5) represents the phylogenetic signal detected from the matrix of 295 Aradidae terminals all longer than 500 bp. Except for the subfamily Carventinae, three other Aradidae subfamilies represented in the matrix are recovered as clades: Aneurinae and Aradidnae (represented by 11 and 14 terminals, respectively; Fig. 2), as well as the most numerous subfamily Mezirinae represented by 223 terminals (Figs 2-5). Most genera represented in the analysis by more than a single species are recovered as clades, except the clade formed by reciprocally paraphyletic Aneurus Curtis, 1825 and Paraneurus Jacobs, 1986 (Fig. 2), polyphyletic Mezira Amyot \& Serville, 1843 and Neuroctenus Hoberlandt, 1967 (Fig. 3), as well as Usum- 


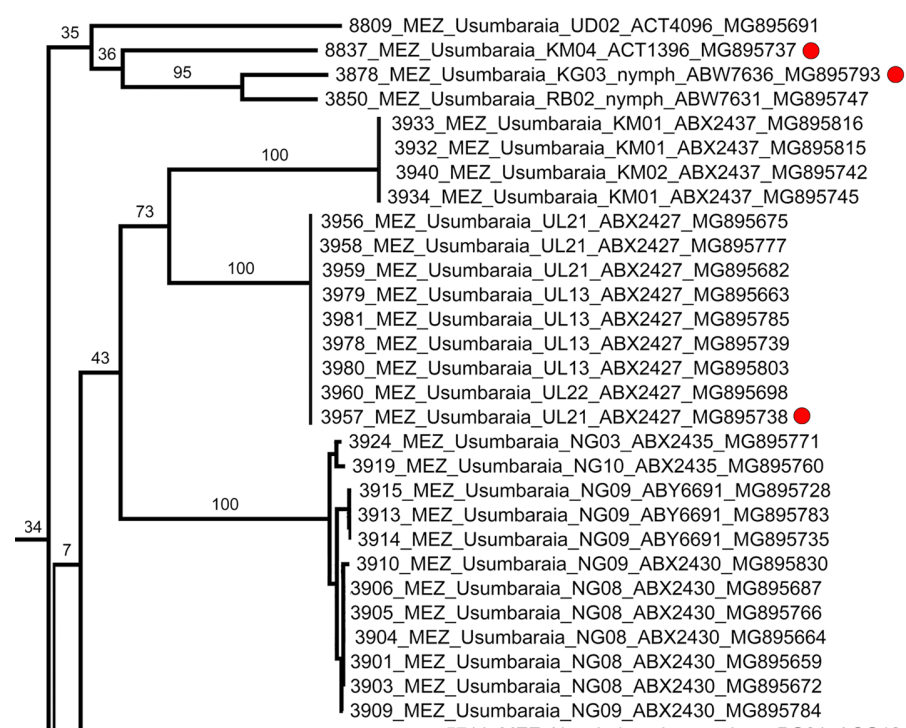

100 3807_MEZ_Usumbaraia_ampliata_EU02 nymph_ABW7628_MG895725 3825_MEZ_Usumbaraia_ampliata_EU08_ABW7628_MG895705 3808 MEZ Usumbaraia ampliata EU02 nymph ABW7628 MG895689 3819 MEZ Usumbaraia EU03 nymph ABW7627 MG895772

100 3816_MEZ_Usumbaraia_EU06_ABW7627_MG895677 3826_MEZ_Usumbaraia_EU02_nymph_ABW7627 MG895821 5776 MEZ Usumbaraia WU07 ABW7627 MG895794 5777 MEZ Usumbaraia WU07 ABW7627 MG895696 5775_MEZ_Usumbaraia_WU07_ABW7627_MG895696 5767 MEZ Usumbaraia WU05_nymph ABW7627 MG895679 5739 MEZ Usumbaraia_NP09_ACG1694_MG895676 8824 MEZ_Usumbaraia_UD07_ACT4098_MG895787 8823_MEZ_Usumbaraia_UD07_ACT4098_MG895711 8819_MEZ_Usumbaraia_UD04_ACT1393_MG895746 100 8820_MEZ_Usumbaraia_UD04_ACT1393_MG895693 8813 MEZ Usumbaraia UD02 ACT1393 MG89566

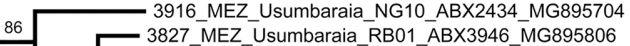
$8 6 \longdiv { - 3 8 2 7 \text { MEZ_Usumbaraia_RB01_ABX3946_MG895806 } }$ 8833_MEZ Usumbaraia_KM04_ABX2433_MG895660 100 3941_MEZ_Usumbaraia KM03_ABX2433_MG895740 3945_MEZ_Usumbaraia_KM03_nymph_ABX2433_MG895763 3939_MEZ_Usumbaraia_KM02_ABX2433_MG895662 3928_MEZ_Usumbaraia_KM01_ABX2433_MG895817 3952_MEZ_Usumbaraia_KM03_ABX2433_MG895810 3853_MEZ_Usumbaraia_RB03_ABW7622_MG895788 3852_MEZ_Usumbaraia_RB03_ABW7622_MG895769 3832_MEZ_Usumbaraia_RB01_ABW7622_MG895801

100 3844_MEZ_Usumbaraia_RB01_nymph_ABW7622_MG895792 3845 MEZ Usumbaraia RB02 ABW7622 MG895743 3864 MEZ Usumbaraia RB04 ABW7622 MG895690 3930 MEZ Usumbaraia KM01_ABY3274_MG895761 3931 MEZ Usumbaraia KM01_ABY3274 MG895694 3954 MEZ Usumbaraia KM03 ABY3960 MG895828

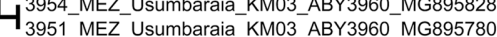

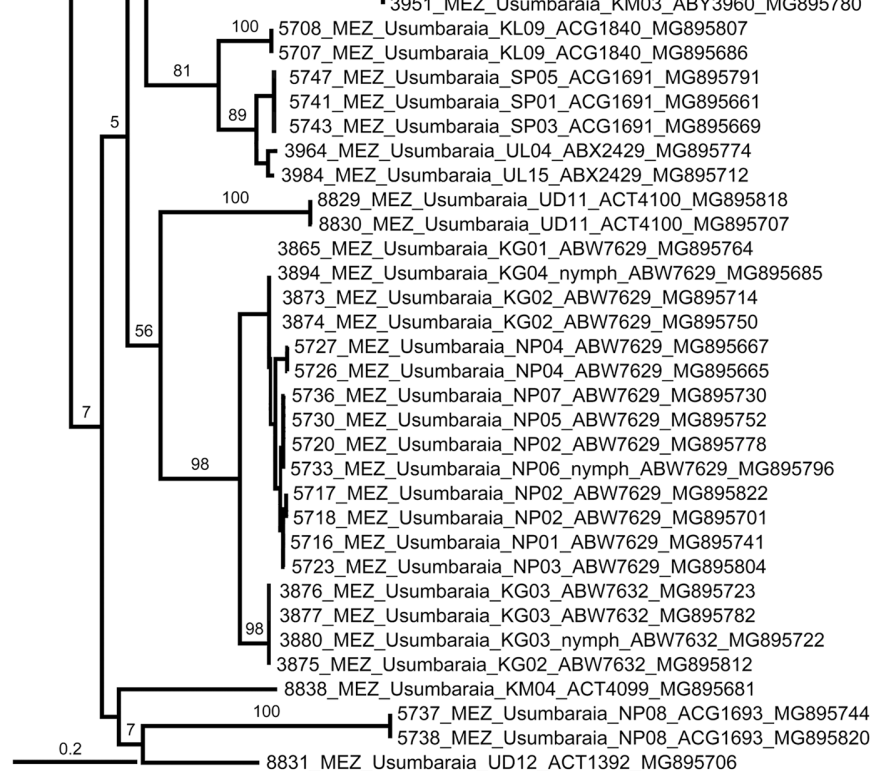

I OTU8809 OTU8837 I OTU3878 I OTU3850 OTU3932

OTU3956

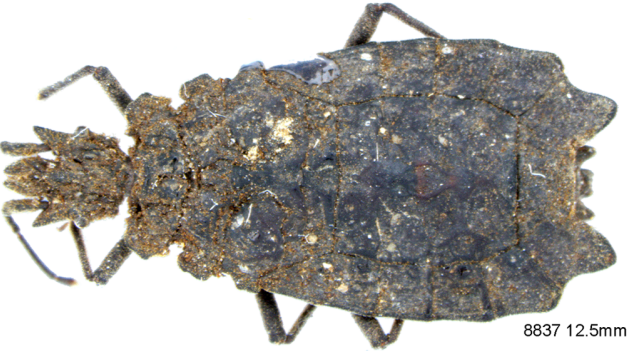

OTU3901

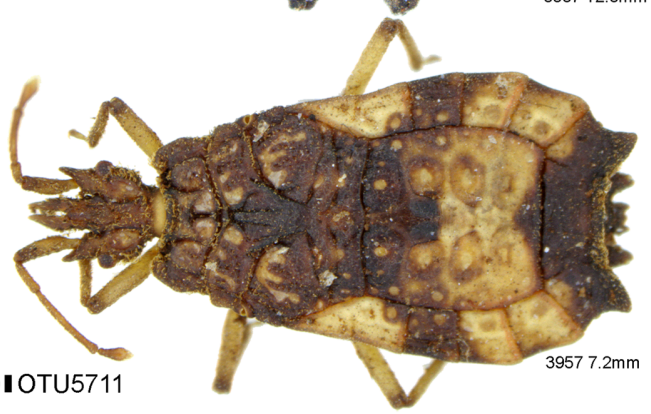

OTU3807

OTU3816

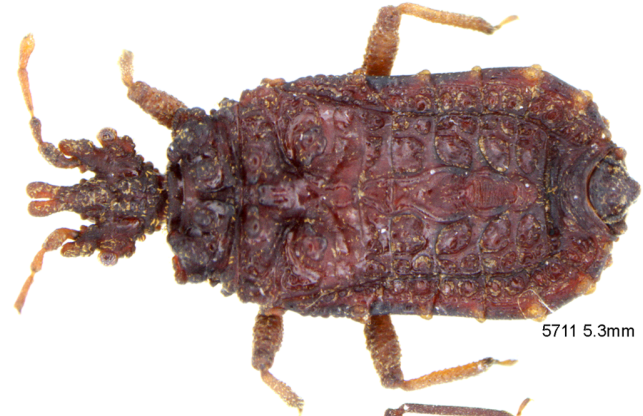

OTU391

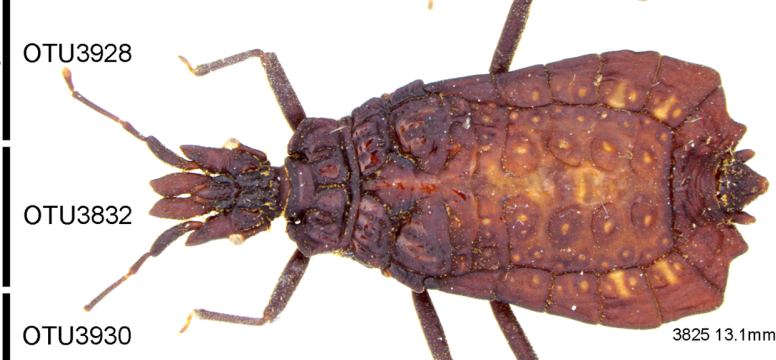

OTU3930

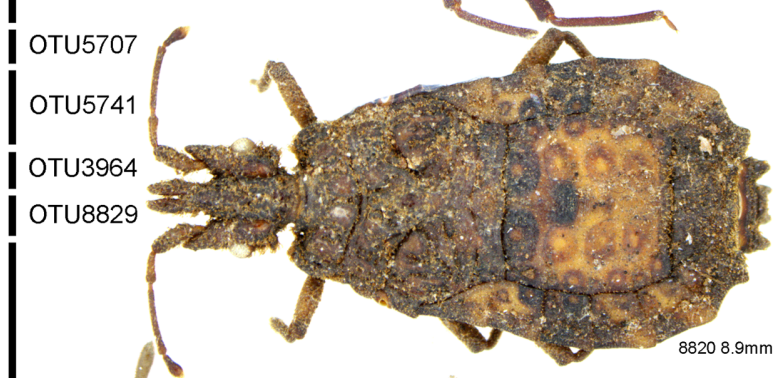

OTU3865

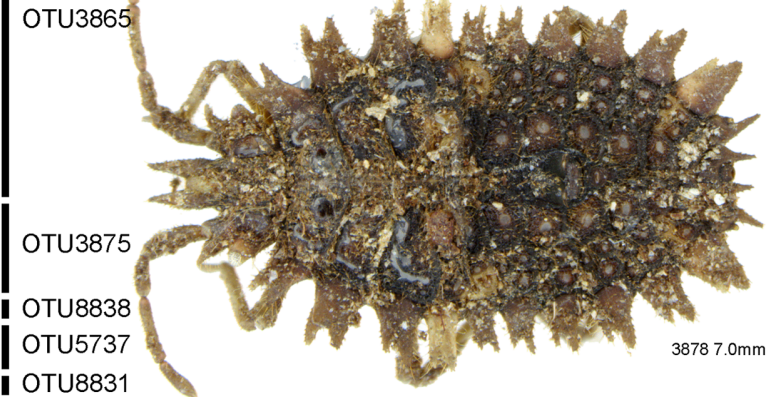

Fig. 5. Maximum Likelihood inference phylogram of Usumbaraia and Neochelonoderus flat bugs (Aradidae: Mezirinae) using the DNA barcoding fragment (continued from Figs 2-4). 
Table 1. Distribution of 63 Aradidae operational taxonomic unites (OTUs) among the 14 Tanzanian localities sampled and among higher taxonomic categories (subfamilies and, when possible, genera and species). The 53 OTUs delimited using the 294 terminal > 500 bp topology (Figs 2-5) are in bold; 10 delimited using morphological characters are italicized. Two OTUs (both in Usumbaraia) each detected at two localities are indicated with an asterisk, followed by a code of another locality.

\begin{tabular}{|c|c|c|c|c|c|c|c|c|c|c|c|}
\hline \multirow[b]{2}{*}{ Locality } & \multirow[b]{2}{*}{ Code } & \multirow{2}{*}{$\frac{\text { Aneurinae }}{\text { Paraneurus }}$} & \multicolumn{2}{|c|}{ Carventinae } & \multicolumn{6}{|c|}{ Mezirinae } & \multirow[b]{2}{*}{$\Sigma$} \\
\hline & & & Dundocoris & $\begin{array}{c}\text { not } \\
\text { assigned }\end{array}$ & Afropictinus & Embuana & $\begin{array}{l}\text { Linnavuo- } \\
\text { riessa }\end{array}$ & $\begin{array}{l}\text { Neochelo- } \\
\text { noderus }\end{array}$ & Usumbaraia & $\begin{array}{c}\text { not } \\
\text { assigned }\end{array}$ & \\
\hline Mt. Hanang & $\mathrm{HN}$ & none & none & none & none & none & none & none & none & none & 0 \\
\hline Mt. Meru & MR & OTU5701 & none & OTU8844 & none & none & none & none & none & none & 2 \\
\hline $\begin{array}{c}\text { Mt. } \\
\text { Kilimanjaro }\end{array}$ & $\mathrm{KL}$ & none & OTU5703 & none & none & none & none & none & OTU5707 & none & 2 \\
\hline North Pare & NP & none & none & none & $\begin{array}{l}\text { OTU5719 (nauplius), } \\
\text { OTU5725 (castor) }\end{array}$ & none & OTU5728 & none & $\begin{array}{c}\text { OTU3865 }^{\star}(\mathrm{KG}), \text { OTU5737, } \\
\text { OTU5739 }\end{array}$ & none & 6 \\
\hline South Pare & SP & none & none & $\begin{array}{l}\text { OTU5744, } \\
\text { OTU5748 }\end{array}$ & OTU5749 (castor) & none & OTU5753 & none & OTU5741 & none & 5 \\
\hline $\begin{array}{l}\text { West } \\
\text { Usambara }\end{array}$ & WU & none & OTU5768 & none & $\begin{array}{l}\text { OTU5761 (castor), } \\
\text { OTU5772 (hylas) }\end{array}$ & none & OTU5759 & none & OTU3816*(EU) & none & 5 \\
\hline $\begin{array}{c}\text { East } \\
\text { Usambara }\end{array}$ & EU & none & none & none & OTU3820 (idas) & none & OTU3813 & none & $\begin{array}{c}\text { OTU3801, OTU3807 } \\
\text { (ampliata), OTU3816*(WU) }\end{array}$ & none & 5 \\
\hline Uluguru & UL & none & none & OTU3982 & OTU3969 (hylas) & OTU3955 & none & none & OTU3956, OTU3964 & none & 5 \\
\hline Nguru & NG & none & none & none & OTU3911 (idas) & none & none & none & $\begin{array}{c}\text { OTU3901, OTU3907, } \\
\text { OTU3916 }\end{array}$ & none & 4 \\
\hline Kaguru & KG & none & OTU3871 & $\begin{array}{l}\text { OTU3867, } \\
\text { OTU3879 }\end{array}$ & OTU3869 (hylas) & none & OTU3866 & none & $\begin{array}{c}\text { OTU3865*(NP), OTU3875, }^{*} \text { OTU3878 }\end{array}$ & none & 8 \\
\hline Rubeho & RB & none & OTU3835 & OTU3861 & none & OTU3838 & OTU3842 & none & $\begin{array}{c}\text { OTU3827, OTU3832, } \\
\text { OTU3850 }\end{array}$ & none & 7 \\
\hline Udzungwa & UD & none & OTU8818 & none & none & none & OTU8825 & none & $\begin{array}{l}\text { OTU8809, OTU8813, } \\
\text { OTU8829, OTU } 8831\end{array}$ & none & 6 \\
\hline Kimboza & KM & none & none & OTU3937 & none & none & none & $\begin{array}{l}\text { OTU3935 } \\
\text { (areius) }\end{array}$ & $\begin{array}{c}\text { OTU3928, OTU3930, } \\
\text { OTU3932, OTU8837, } \\
\text { OTU8838 }\end{array}$ & none & 7 \\
\hline Pugu & PG & none & none & none & none & none & none & $\begin{array}{l}\text { OTU5711 } \\
\text { (talus) }\end{array}$ & none & $\begin{array}{l}\text { OTU5710, } \\
\text { OTU5714 }\end{array}$ & 3 \\
\hline$\Sigma$ & & 1 & 5 & 8 & 9 & 2 & 7 & 2 & 27 & 2 & \\
\hline
\end{tabular}

baraia Kormliev, 1956, which is paraphyletic with respect to a representative of Neochelonoderus (Fig. 5).

\section{Neighbour Joining analysis of Aradidae}

The NJ topology of 209 Tanzania-only Aradidae terminals longer than 200 bp (Fig. S2) was mainly consistent with that obtained in the ML analysis (Figs 2-5) in recovering allopatric clusters of terminals.

\section{Formation of Tanzanian Aradidae OTUs}

Of the total of 63 OTUs representing the entire diversity of Tanzanian Aradidae sampled (Table 1), 53 are represented in the ML topology obtained from the 295 terminal matrix (Figs 2-5). Ten more OTUs are formed by sequenced specimens not represented in Figs 2-5: OTU3801 from East Usambara (specimen CNCCOLVG00003801), OTU3835 from Rubeho (specimens CNCCOLVG00003835, 3837 and likely specimens 3834, 3855, 3856), OTU3871 from Kaguru (specimens CNCCOLVG00003871, 3872), OTU3879 from Kaguru (specimens CNCCOLVG00003879, 3892, 3889, 3891), OTU3907 from Nguru (specimens CNCCOLVG00003907, 3908, 3912, 3925, 3926, 3927), OTU3935 from Kimboza (specimens CNCCOLVG00003935, 3936, 3942, 3943, 4757, 4758, 4759), OTU3982 from Uluguru (specimen CNCCOLVG00003982), OTU5710 from Pugu Hills (specimen CNCCOLVG00005710), OTU8818 from Uluguru (specimens CNCCOLVG00008818, 8815, 8817, 8821,
8822) and OTU8844 from Mt. Meru (specimens CNCCOLVG00008844, 8845, 8847).

\section{Distribution of Tanzanian Aradidae OTUs among sampled localities and taxa}

Distribution of 63 OTUs among the14 localities sampled in Tanzania (Table 1) varies between nil (Mt. Hanang, i.e. no Aradidae collected) and seven (on each of the Rubeho and Pugu Hills). The highest diversity of OTUs occurred in the genus Usumbaraia (27), followed by Afropictinus (9) and Linnavuoriessa Heiss \& Baňař, 2016 (7). Seven Carventinae and two Mezirinae OTUs could not be assigned to a named genus. Except for the 11 OTUs belonging to the recently revised Neochelonoderus (2) and Afropictinus (9), all but one (OTU3807, Usumbaraia ampliata Kormliev, 1956) Tanzanian OTUs could not be assigned to a named species.

\section{Winglessness in Tanzanian Aradidae}

Except for three OTUs formed by winged specimens [OTU5701 from Mt. Meru; OTU5710 and OTU5714 (Fig. 1B) from Pugu Hills], all the Tanzanian Aradidae analyzed are apterous.

\section{DISCUSSION}

Hypothesis 1: Aradidae of Tanzania are well known taxonomically at the generic and species level

Since $52(83 \%)$ and $12(19 \%)$ among the total of 63 Tanzanian Aradidae OTUs were assigned to a named genus 
and species (Table 1), respectively, this hypothesis could not be rejected with regard to genera, and is strongly rejected with regard to species.

\section{Hypothesis 2: shallow clades of Aradidae in TFA are geographically structured}

Since only two among 53 DNA-based OTUs were detected at more than a single TFA location (OTU3865 found at both Kaguru and North Pare, and OTU3816 found at both East Usambara and West Usambara, Table 1), our results do not reject this hypothesis.

\section{Hypothesis 3: all the phylogeographic structure of Aradidae in TFA can be attributed to simple vicariance}

Since reciprocal monophyly of all but two DNA-based OTUs is best interpreted as the standard signature of simple vicariance of a widespread ancestor (Heads 2014: 6), and since at least one non-endemic OTU (OTU3816) was detected at two nearby TFA localities (West and East Usambara), this hypothesis cannot be rejected.

\section{Hypothesis 4: Aradidae faunas on geologically young Tanzanian volcanoes were formed anew after the volcanic highlands and their forests came into existence about two million years ago}

Data in Table 1 indicate that the mean diversity of Aradidae OTUs on all three volcanoes (Mts Hanang, Meru and Kilimanjaro) is only 1.33 species $(\mathrm{n}=3$, standard deviation $\mathrm{s}=1.15)$, which is far less than the same value for nine $\operatorname{EAM}(5.67, \mathrm{~s}=1.22)$ and two lowland forests $(5, \mathrm{~s}=2.83)$. Such results indicate a depauperate Aradidae fauna on Tanzanian volcanoes, as compared to other samples from TFA localities and, therefore, do not reject this hypothesis.

\section{Hypothesis 5: If $\mathrm{H} 4$ is supported, then this process was driven by colonization from nearby and geologically older TFA forests}

Since the distance between a volcano and the nearest EAM (greatest for Mt. Hanang, Fig. 1A) potentially serving as a source of Aradidae is inversely proportional to the diversity of Aradidae on the three volcanoes sampled (lowest for Mt. Hanang, Table 1), this hypothesis cannot be rejected.

\section{Diversity of Aradidae in the Tanzanian Forest Archipelago}

Adequate background taxonomic information is commonly lacking for insects sampled outside a few centers of taxonomic expertise, such as Europe, Japan or North America (see, for example, a report of over 4,000 mainly unnamed species of Diptera from a single four hectare spot in Costa Rica, Borkent et al., 2018). Tanzanian Aradidae are not an exception, and, therefore, being unable to count nominal species, we had to generate, count and compare ad hoc created OTUs (Table 1). It is likely that the latter adequately represents species diversity in individual units of the TFA, which varies between nil (Mt. Hanang) and eight (Kaguru; $\mathrm{n}=14$, mean 4.64, standard deviation 2.24). The same approach, however, will likely inflate the number of species when OTUs are counted within individual genera (with the maximum of 27 OTUs recorded for Usumbaraia), since at least in the genus Afropictinus nine OTUs correspond to four nominal species (Table 1). It should be noted, however, that a biological species is not an objective category (Ward, 2011) and, therefore, is perhaps more familiar, but not intrinsically better, than OTUs for diversity assessments.

Of the total of five genera and nine species reported from the country prior to this study [Paraneurus (1 sp.), Brachyrhynchus Laporte, 1833 (1 sp.), Mezira (2 spp.), Neuroctenus (3 spp.) and Usumbaraia (2 spp.); Heiss, 2013], we re-sampled two: Paraneurus and Usumbaraia. It should be also noted that two additional genera with a total of six new species were added by us to the Tanzanian faunal list: Neochelonoderus (2 spp., Heiss \& Grebennikov, 2015) and Afropictinus (4 spp., Heiss \& Grebennikov, 2016) and they are not included as a part of the pre-existing knowledge used here for comparison. The Aradidae fauna of broadly defined East Africa (from Ethiopia to Zimbabwe) was reported by Heiss (2013) to consist of 16 genera and 37 species. Since then we added three new species of Neochelonoderus and six of Afropictinus (Heiss \& Grebennikov, 2015 and 2016, respectively) and Heiss \& Baňař (2016) established two new monotypic genera endemic to Kenya, Embuana Heiss \& Baňař, 2016 and Linnavuoriessa. Of these 18 East African genera we re-sampled only seven (39\%), possibly because the rest inhabit places other than leaf litter: Aneurinae: Aneurillus Kormilev, 1968 and Breviscutaneurus Jacobs, 1986; Aradinae: Aradus Fabricius, 1803; Calisiinae: Calisius Stål, 1860 \& Paracalisiopsis Kormilev, 1963; Mezirinae: Rwandaptera Heiss, 2001, Brachyrhynchus Laporte, 1833, Ctenoneurus Bergroth, 1887, Mezira, Neuroctenus \& Strigocoris Usinger, 1954). Excluding the new species of Neochelonoderus and Afropictinus described by us from the herein reported Tanzanian samples, our samples contain only a single nominal species: U. ampliata Kormliev, 1956. Such results strongly suggest that the Aradidae fauna of Tanzania is far from being completely documented.

The subfamily Aneurinae is represented in TFA by a single OTU of the genus Paraneurus, found only on Mt. Meru (Fig. 2, Table 10). Described originally as the "most heterogeneous" subgenus of African Aneurinae (Jacobs, 1986) and later arbitrarily elevated to the generic level (Kormilev \& Froeschner, 1987), this genus-group taxon renders Aneurus non-monophyletic (Fig. 2) and sheds significant doubt on its phylogenetic validity.

The subfamily Carventinae is represented in TFA by 13 OTUs, five of which are assigned to the genus Dundocoris, while the remaining eight form at least three clades (Fig. 2) and perhaps represent undescribed genera.

The subfamily Mezirinae is by far the most diverse in TFA and accounts for 49 of the 63 recorded OTUs (Table 1). Two among five recorded nominal Mezirinae genera were recently revised by us (Neochelonoderus and Afropictinus, Heiss \& Grebennikov, 2015 and 2016, respectively) and no new data on them are herein provided. The 
genera Embuana and Linnavuoriessa are newly recorded from Tanzania and are likely represented by species other than their type, the only known species recently described from Kenya (Heiss \& Baňar̆, 2016). The remaining nominal genus, Usumbaraia, with its 27 OTUs (Table 1) is by a wide margin the most diversified genus of Aradidae in TFA accounting for more than half of all Mezirinae (49) and nearly half of all Aradidae (63) OTUs. The genus is likely a clade, even though a single analyzed Neochelonoderus is nested within it (Fig. 5), and includes the largest Tanzanian Aradidae, which reach $13 \mathrm{~mm}$ in body length. It should be noted that the genus Vilhenaptera Hoberlandt, 1967 formed by a single species $V$. angolensis Hoberlandt, 1967 from Angola, seems either most closely related to, or perhaps nested within, Usumbaraia.

Two Mezirinae OTUs, both represented by a single macropterous specimen, could not be assigned to a named genus (Table 1). Among them, OTU5710 is represented by a specimen that is not DNA-barcoded (Fig. 1B), whose large size and the shape of its pronotum suggest Linnavuoriessa, rather than those of the much smaller Embuana. The specimen displays, however, two characters not recorded in either genus, namely: fully developed wings and the absence of bicoloured laterosternites. As for the single and much smaller male specimen representing OTU5714, it resembles the notably larger Linnavuoriessa, has distinct ventral stridulatory structures, and a peculiar location of the abdominal spiracles (II-V ventral, VI ventrolateral, VII lateral), which either suggests a new genus-group taxon or, considering its placement in the Embuana + Linnavuories$s a$ clade (Fig. 3), re-definition of these taxa.

It should be noted that the Aradidae phylogenetic tree (Figs 2-5) is similar to a tree reported earlier by us (Grebennikov \& Heiss, 2014). Specifically, all represented nominal taxa are monophyletic, except the subfamily Carventinae and the genera Neuroctenus, Mezira and Usumbaraia. These topological similarities are partly expected, since the herein used matrix was formed by extending the 2014 matrix to include Tanzanian and a few other specimens. Still, the monophyly of Mezirinae, forming $75 \%$ of the new matrix, is newly and vigorously re-tested (since the addition of Tanzanian samples greatly diversified this subfamily' representation) and was found to be strongly supported. Tanzanian nominal genera Dundocoris Hoberlandt, 1952, Linnavuoriessa, Embuana and Afropictinus each represented by more than a single terminal are all recovered as monophyletic, while the paraphyly of Usumbaraia with respect to a single included Neochelonoderus (Fig. 5) is likely an analytical artifact, possibly attributable to long branch attraction. These results suggest that notwithstanding its well-known limitations (i.e. Funk \& Omland, 2003), the DNA barcode fragment might be of phylogenetic value, particularly in the not infrequent situation when it is the only readily available source of information (see also Wilson et al., 2011 or Grebennikov et al., 2017).

Finally, it is tempting to compare this updated faunal knowledge of East African Aradidae (see above) with that of nearby Madagascar, with 35 genera and 90 species of
Aradidae (Heiss, 2012; Baňař \& Heiss, 2018). Both faunas share at least seven nominal genera (Breviscutaneurus Jacobs, 1986, Aradus Fabricius, 1803, Brachyrhynchus, Ctenoneurus Bergroth, 1884, Mezira, Neuroctenus and Stigocoris Usinger, 1954) and two nominal species (Aradus flavicornis Dalman, 1823 and Neuroctenus caffer Stål, 1860); all of these taxa contain macropterous and likely actively flying bugs. These facts, however, can hardly shed adequate light on the classic question as to whether vicariance or dispersal was the predominant biogeographic force in Madagascar (Yoder \& Nowak, 2006), since the phylogenetic relationships within the family remain inadequately known and at least three among seven shared genera (Aradus, Mezira, Neuroctenus) are found in more than a single zoogeographical region.

ACKNOWLEDGEMENTS. C. Weirauch (Riverside, CA, USA) and A. Brunke (Ottawa, Canada) critically read an earlier draft of this paper; P. Baňař (Brno, Czech Republic) and P. Kment (Prague, Czech Republic) reviewed it.

\section{REFERENCES}

BAŇAR̆ P. \& Heiss E. 2018: A new species of Comorocoris from Northern Madagascar (Hemiptera: Heteroptera: Aradidae). Zootaxa 4375: 433-440.

Brokent A., Brown B.V., Adler P.H., Amorim D.S., Barber K., Bickel D., Boucher S., Brooks S.E., Burger J., Burington Z.L. ET AL. 2018: Remarkable fly (Diptera) diversity in a patch of Costa Rican cloud forest: why inventory is a vital science. - Zootaxa 4422: 53-90.

CAssis G. \& Schun R.T. 2010: Systematic methods, fossils, and relationships within Heteroptera (Insecta). - Cladistics 26: 262-280.

Chérot F., Aukema B., Bruers J. \& Viskens G. 2011: Exotic species of Aradidae and Miridae (Insecta: Hemiptera, Heteroptera) recently found in Antwerp Harbour, Belgium. - Bull. Soc. R. Belge Entomol. 147: 14-19.

Collins R.A. \& Cruickshank R.H. 2013: The seven deadly sins of DNA barcoding. - Mol. Ecol. Res. 13: 969-975.

deMenocal P.B. 2004: African climate change and faunal evolution during the Pliocene-Pleistocene. - Earth Planet. Sci. Lett. 220: 3-24.

Grazia J., Schun R.T. \& Wheeler W.C 2008: Phylogenetic relationships of family groups in Pentatomoidea basedon morphology and DNA sequences (Insecta: Heteroptera). — Cladistics 24: 932-976.

Grebennikov V.V. 2017: Phylogeography and sister group of Lupangus, a new genus for three new flightless allopatric forest litter weevils endemic to the Eastern Arc Mountains, Tanzania (Coleoptera: Curculionidae, Molytinae). — Fragm. Entomol. 49: $37-55$.

GreBenNiKov V.V. \& HeIss E. 2014: DNA barcoding of flat bugs (Hemiptera: Aradidae) with phylogenetic implications. Arthr. Syst. Phylogeny 72: 213-219.

Grebennikov V.V., Jendek E. \& SMirnov M.E. 2017: Diagnostic and phylogenetic utility of the first DNA barcode library for longhorn beetles (Coleoptera: Cerambycidae) from the Russian Far East. — Zootaxa 4276: 441-445.

Felsenstein J. 1985: Confidence limits on phylogenies: an approach using the bootstrap. - Evolution 39: 783-791.

FunK D.J. \& OMLand K.E. 2003: Species-level paraphyly and polyphyly: frequency, causes, and consequences, with insights 
from animal mitochondrial DNA. - Annu. Rev. Ecol. Evol. Syst. 34: 397-423.

Hamilton A.C. \& TAYloR D. 1991: History of climate and forests in tropical Africa during the last 8 million years. - Clim. Change 19: 65-78.

Havemann N., Gossner M.M., Hendrich L., Morinière J., NieDRINGHAUS R., SCHÄFER P. \& RAUPACH M.J. 2018: From water striders to water bugs: the molecular diversity of aquatic Heteroptera (Gerromorpha, Nepomorpha) of Germany based on DNA barcodes. - PeerJ 6: e4577, 30 pp.

Heads M. 2014: Biogeography of Australasia. A Molecular Analysis. Cambridge University Press, Cambridge, 503 pp.

Hebert P.D.N., Cywinska A., Ball S.L. \& DeWaArd J.R. 2003a: Biological identifications through DNA barcodes. - Proc. $R$. Soc. (B) 270: 313-321.

Hebert P.D.N., Ratnasingham S. \& DeWaard J.R. 2003b: Barcoding animal life: cytochrome c oxidase subunit 1 divergences among closely related species. — Proc. R. Soc. (B) 270: 96-99.

Heiss E. 2012: Annotated catalogue of the flat bug family Aradidae Brullé, 1836 of Madagascar and adjacent islands (Hemiptera: Heteroptera). - Zootaxa 3426: 45-63.

HeIss E. 2013: Annotated checklist of the flat bug family Aradidae Brullé, 1836 from East Africa (Hemiptera, Heteroptera). -Zootaxa 3718: 331-344.

Heiss E. \& BAŇAř P. 2016: Two new genera of micropterous Mezirinae from Kenya (Hemiptera: Heteroptera: Aradidae). Entomol. Amer. 122: 18-23.

Heiss E. \& Grebennikov V.V. 2015: Review and three new species of the flat bug genus Neochelonoderus Hoberlandt, 1967 from East Africa (Hemiptera: Heteroptera: Aradidae). — Zootaxa 3947: 581-589.

Heiss E. \& GrebenNiKov V.V. 2016: Monophyly, review, six new species and DNA barcode of micropterous Afromontane Afropictinus (Heteroptera: Aradidae). — Zootaxa 4208: 149-160.

Hendrich L., Morinière J., Haszprunar G., Hebert P.D.N, Hausmann A., KöHLer F. \& Balke M. 2015: A comprehensive DNA barcode database for Central European beetles with a focus on Germany: adding more than 3500 identified species to BOLD. - Mol. Ecol. Res. 15: 795-818.

IVAnova N.V., DeWaArd J.R. \& Hebert P.D.N. 2006: An inexpensive, automation-friendly protocol for recovering high-quality DNA. - Mol. Ecol. Notes 6: 998-1002.

Ivanova N.V., DeWaArd J.R., Hajibabaei M. \& Hebert P.D.N. 2014: Protocols for high-volume DNA barcode analysis. URL: https://www.researchgate.net/profile/Paul_Hebert2/ publication/238509959 Protocols for_High-Volume DNA Barcode_Analysis/links/53d169190cf220632f393902/ Protocols-for-High-Volume-DNA-Barcode-Analysis. pdf?origin=publication_detail

JACOBS D.H. 1986: Morphology and taxonomy of sub-saharan Aneurus species with notes on their phylogeny, biology and cytogenetics (Heteroptera: Aradidae: Aneurinae). - Entomol. Mem. Dep. Agric. Tech. Tech. Serv. Rep. S. Afr. 64: 1-45.

Kormilev N.A. \& Froeschner R.C. 1987: Flat bugs of the World. A synonymic list (Heteroptera: Aradidae). - Entomography 5: $245 \mathrm{pp}$

LARIVIÈRE M.-C. \& LAROChelle A. 2006: An overview of flat bug genera (Hemiptera, Aradidae) from New Zealand, with considerations of faunal diversification and affinities. - Denisia 9: $181-214$.

Lees D.C., Kawahara A.Y., Rougerie R., Ohshima I., Kawakita A., Bouteleux O, De Prins J. \& Lopez-Vaamonde C. 2014 DNA barcoding reveals a largely unknown fauna of Gracillariidae leaf-mining moths in the Neotropics. - Mol. Ecol. Res. 14: $289-296$
Liu Y., Song F., Jiang P., Wilson J.-J., CaI W. \& Li H. 2018: Compositional heterogeneity in true bug mitochondrial phylogenomics. - Mol. Phylogenet. Evol. 118: 135-144.

LOVETT J.C. \& WASSER S.K. (eds) 1993: Biogeography and Ecology of the Rain Forests of Eastern Africa. Cambridge University Press, Cambridge, $341 \mathrm{pp}$.

Marchal L. \& Guilbert E. 2015: Cladistic analysis of Aradidae (Insecta, Heteroptera) based on morphological and molecular characters. - Zool. Scr. 45: 273-285.

Miller M., Pfeiffer W. \& Schwartz T. 2010: Creating the CIPRES Science Gateway for inference of large phylogenetic trees. In: Proceedings of the Gateway Computing Environments Workshop (GCE), 14 Nov. 2010, New Orleans, LA. pp. $1-8$.

Monteith G.B. 1997: Revision of the Australian flat bugs of the subfamily Mezirinae (Insecta: Hemiptera: Aradidae). - Mem. Qld Mus. 41: 1-169.

Newmark W.D. 2002: Conserving Biodiversity in East African Forests: A study of the Eastern Arc Mountains. Ecological Studies 155. Springer, Berlin, 205 pp.

Nonnotte P., Guillou H., Le Gall B., Benoit M., Cotton J. \& SCAILlET S. 2008: New K-Ar age determinations of Kilimanjaro volcano in the North Tanzanian diverging rift, East Africa. - J. Volcanol. Geotherm. Res. 173: 99-112.

Popper K. 1959: The Logic of Scientific Discovery. Basic Books, New York, 484 pp.

Rambaut A. 2014: FigTree, Version 1.4. URL: http://tree.bio. ed.ac.uk/software/figtree/ (last accessed 12 Mar. 2014).

Raupach M.J., Hendrich L., Küchler S.M., Deister F., MorinIÈrE J. \& Gossner M.M. 2014: Building-Up of a DNA barcode library for true bugs (Insecta: Hemiptera: Heteroptera) of Germany reveals taxonomic uncertainties and surprises. - PLoS ONE 9: e106940, 13 pp.

Ratnasingham S. \& Hebert P.D.N. 2007: BOLD: The Barcode of Life Data System (http://www. barcodinglife. org). - Mol. Ecol. Notes 7: 355-364.

Ratnasingham S. \& Hebert P.D.N. 2013: A DNA-based registry for all animal species: the Barcode Index Number (BIN) system. - PLoS ONE 8: e66213, 16 pp.

Rougerie R., Kitching I.J., HaXaire J., Miller S.E., Hausmann A. \& Hebert P.D.N. 2014: Australian Sphingidae - DNA barcodes challenge current species boundaries and distributions. - PLOS ONE 9(7): e101108, 12 pp.

Schmidt S., Schmid-Egger C., Morinière J., Haszprunar G. \& HeBert P.D.N. 2015: DNA barcoding largely supports 250 years of classical taxonomy: identifications for Central European bees (Hymenoptera, Apoidea partim). - Mol. Ecol. Res. 15: $985-1000$.

Schun R.T. \& Slater J.A. 1995: True Bugs of the World (Hemiptera: Heteroptera): Classification and Natural History. Cornell University Press, Ithaca, NY, 336 pp.

Shorthouse D.P. 2010: SimpleMappr, an Online Tool to Produce Publication-Quality Point Maps. URL: http://www.simplemappr.net

Song F., Li H., Shao R., Shi A., Bai X., Zheng X., Heiss E. \& CAI W. 2016: Rearrangement of mitochondrial tRNA genes in flat bugs (Hemiptera: Aradidae). - Sci. Rep. 6: 25725, 9 pp.

Smith-Pardo A.H. \& Beucke K. 2015: Flat Bugs (Hemiptera: Heteroptera: Aradidae) intercepted at United States ports of entry. - Pan-Pac. Entomol. 91: 58-81.

Stamatakis A., Hoover P. \& Rougemont J. 2008: A rapid bootstrap algorithm for the RAxML web servers. - Syst. Biol. 57: 758-771.

Usinger R.L. \& MATSUdA R. 1959: Classification of the Aradidae. British Museum of Natural History, London, 410 pp. 
Vences M., Guayasamin J.M., Miralles A. \& De La Riva I. 2013: To name or not to name: criteria to promote economy of change in Linnaean classification schemes. - Zootaxa 3636: 201-244.

WARD P.S. 2011: Integrating molecular phylogenetic results into ant taxonomy (Hymenoptera: Formicidae). - Myrmecol. News 15: 21-29.

Wilson J.J., Rougerie R., Schonfeld J., Janzen D.H., Hallwachs W., Hajibabaei M., Kitching I.J., HaXaire J. \& Hebert P.D.N. 2011: When species matches are unavailable are DNA barcodes correctly assigned to higher taxa? An assessment using sphingid moths. - BMC Ecol. 11: 18, 14 pp.

USINGER R.L. \& MATSUDA R. 1959: Classification of the Aradidae (Hemiptera - Heteroptera). British Museum of Natural History, London, $410 \mathrm{pp}$.

YAO Y., Ren D., RIDER D.A. \& CAI W. 2012: Phylogeny of the infraorder Pentatomomorpha based on fossil and extant morphology, with description of a new fossil family from China. - PLOS ONE 7(5): e37289, 17 pp.
Yoder A.D. \& NowAK M.D. 2006: Has vicariance or dispersal been the predominant biogeographic force in Madagascar? Only time will tell. - Annu. Rev. Ecol. Evol. Syst. 37: 405-431.

Zahiri R., Lafontaine J.D., Schmidt C.C., Zakharov E.V. \& HeBERT P.D.N. 2017: Probing planetary biodiversity with DNA barcodes: The Noctuoidea of North America. — PLOS ONE 12: $\mathrm{e} 0178548,18 \mathrm{pp}$.

Received May 4, 2018; revised and accepted August 15, 2018 Published online September 26, 2018

Supplementary file: http://www.eje.cz/2018/051/S01.pdf.

Fig. S1. Images of 300 Tanzanian Aradidae submitted for DNA barcoding.

Fig. S2. Neighbour joining clustering of 209 Tanzanian Aradidae, for which DNA barcodes of $>200 \mathrm{bp}$ were obtained using the online BOLD tree-building engine and Kimura 2 parameter. 